\title{
Use of a generic protocol in documentation of prescription errors in Estonia, Norway and Sweden
}

\author{
Daisy VOLMER, Svein HAAVIK, Anders EKEDAHL.
}

\begin{abstract}
$^{*}$
Pharmacists have an important role in detecting, preventing, and solving prescription problems, which if left unresolved, may pose a risk of harming the patient.

Objective: The objectives of this study were to evaluate the feasibility of a generic study instrument for documentation of prescription problems requiring contact with prescriber before dispensing. The study was organized: 1) by countries: Estonia, Norway and Sweden; 2) by type of prescriptions:

handwritten prescriptions, printouts of prescriptions in the electronic medical record and electronically transmitted prescriptions to pharmacies; and 3) by recording method - self-completion by pharmacists and independent observers.
\end{abstract}

Methods: Observational study with independent observers at community pharmacies in Estonia $(n=4)$ and Sweden $(n=7)$ and self-completed protocols in Norway $(n=9)$.

Results: Pharmacists' in Estonia contacted the prescriber for $1.47 \%$ of the prescriptions, about 3 times as often as in Norway $(0.45 \%)$ and Sweden $(0.38 \%)$. Handwritten prescriptions dominated among the problem prescriptions in Estonia $(73.2 \%)$, printouts of prescriptions in the electronic medical record (89.1\%) in Norway and electronically transmitted prescriptions to pharmacies $(55.9 \%)$ in Sweden.

More administrative errors were identified on handwritten prescriptions and printouts of prescriptions in the electronic medical record in Estonia and in Norway compared with electronically transmitted prescriptions to pharmacies in Sweden $(p<0.05$ for prescription types and $p<0.01$ for countries). However, clinically important errors and delivery problems appeared equally often on the different types of prescriptions. In all three countries, only few cases of drug interactions and adverse drug reactions were identified.

Conclusion: Despite the different patterns of prescription problems in three countries, the instrument was feasible and can be regarded appropriate to document and classify prescription problems necessitating contact with prescriber before dispensing, irrespective of the type of prescription or recording method.

\footnotetext{
Daisy VOLMER. PhD. Department of Pharmacy, University of Tartu. Tartu (Estonia).

Svein HAAVIK. PhD. Centre for Pharmacy, University of Bergen. Bergen (Norway).

Anders EKEDAHL. PhD. Department of Rational Use of Medications, Medical Products Agency, Uppsala, Sweden; Linnæus University. Kalmar (Sweden).
}

Keywords: Medication Errors. Patient Safety. Community Pharmacy Services. Estonia. Norway. Sweden.

\section{USO DE UN PROTOCOLO GENÉRICO EN LA DOCUMENTACIÓN DE LOS ERRORES DE PRESCRIPCIÓN EN ESTONIA, NORUEGA Y SUECIA}

\section{RESUMEN}

Los farmacéuticos juegan un papel importante en la detección, prevención y resolución de problemas de prescripción, que si no se resuelven pueden poner en riesgo de daño al paciente.

Objetivo: Los objetivos de este estudio fueron evaluar la factibilidad de un instrumento de genérico de estudio para documentar los problemas de prescripción que requieren contactar al prescriptor antes de dispensar. El estudio se organizó: 1) por países: Estonia, Noruega y Suecia; 2) por tipo de recetas: recetas manuscritas, recetas impresas desde el historial electrónico del médico, y prescripción electrónica; y 3) por método de registro: auto-cumplimentación por los farmacéuticos o por observadores independientes. Métodos: Estudio observacional con observadores independientes en las farmacias comunitarias en Estonia $(n=4)$ y Suecia $(n=7)$ y protocolos autocumplimentados en Noruega $(\mathrm{n}=9)$.

Resultados: Los farmacéuticos en Estonia contactaron a los prescriptores en el $1.47 \%$ de las recetas, unas 3 veces más frecuentemente que en Noruega $(0.45 \%)$ y Suecia $(0.38 \%)$.Las recetas manuscritas dominaron entre los problemas de prescripción en Estonia (73.2\%), las impresiones de recetas desde el historial electrónico $(89.1 \%)$ en Noruega, y las prescripciones electrónicamente transmitidas a las farmacias $(55.9 \%)$ en Suecia. Se identificaron más errores administrativos en las recetas manuscritas y en las impresas desde el historial electrónico en Estonia y Noruega, comparadas con las electrónicamente transmitidas a la farmacia de Suecia $(\mathrm{p}<0.05$ para los tipos de recetas y $\mathrm{p}<0.01$ para los países). Sin embargo, los errores clínicamente importantes y los problemas de entrega aparecieron igualmente entre los diferentes tipos de recetas. En los tres países, se identificaron unos pocos casos de interacciones medicamentosas y de reacciones adversas.

Conclusión: A pesar de los tres patrones diferentes de prescripción en los tres países, el instrumento fue factible y puede considerarse apropiado para documentar y clasificar los problemas de prescripción que necesitan contactar con el 
prescriptor antes de ser dispensados,

independientemente del tipo de receta o del método de registro.

Palabras clave: Errores de Medicación. Seguridad del paciente. Servicios de Farmacia Comunitaria. Estonia. Noruega. Suecia.

\section{INTRODUCTION}

Prescribing errors are defined as prescribing decision or mistakes in the prescription writing process that result in unintentional significant reduction in the probability of timely and effective treatment or an increase in the risk of harm. Prescribing errors are a common cause for preventable medication errors and adverse drug events in primary care. ${ }^{1}$ Frequent occurring prescription errors include incorrect selection of medication for the patient including the dose, quantity, indication, or the prescribing a contraindicated medication. ${ }^{2}$

Community pharmacists have an important role in detecting, preventing, and solving prescription problems, which if left unresolved, may pose a risk of harming the patient. ${ }^{3}$ Pharmacists intervene to eliminate or minimize these risks, often by contacting the prescriber with suggestions to change the medication. ${ }^{4}$ In studies that have judged the clinical importance of pharmacists' actions, it was found that their actions were clinically relevant and approved by the prescribers in most cases. ${ }^{5-8}$

However, the recorded rates of prescription problems at pharmacies are composed of prescription error rates, detection rates, and actions taken, as well as recording rates. Detection and action rates by pharmacists are influenced by pharmacy size, location, organization of work and work load of the pharmacy ${ }^{9}$ and available information concerning patient and prescribed medication. ${ }^{10}$

Prescription error rates may vary with prescribers, licensing examination scores, medical speciality, experience, practice group structure and culture, and the number of doctors involved in prescribing to the patient. Error rates may also vary with the design of the prescription form and how the prescription is generated (handwritten prescription, prescriptions produced in the electronic medical record and electronically transmitted prescriptions to pharmacies). ${ }^{11-15}$ Error rates are higher with handwritten prescriptions, where ambiguous instructions and interpretation errors and administrative errors, such as missing prescriber or patient data, may constitute a large part of the recorded prescription problems. ${ }^{11}$

Pharmacists' detection, recording, and action rates of prescription errors are influenced by pharmacy size, location, organization, workload, available information (such as presence on the prescription of indication or intended use), access to patient record or patient medication profile, attendance of the patient or a representative at the pharmacy to have the prescription dispensed, and the individual pharmacists' education and training.

Recording rates may vary with recording method and appropriateness and feasibility of recording instruments used. Different instruments have been used in different studies, but few of them have been evaluated. Some may have been developed for classification of prescription problems in the context of handwritten prescriptions, others for use in situ in a specific local context or study. Furthermore, in a context where mainly printouts of prescriptions in the electronic medical record and electronically transmitted prescriptions to pharmacies are used, previous classifications may be obsolete, and the error pattern may have changed. Errors commonly encountered with handwritten prescriptions may have resolved but new clinically significant errors such as incorrect drug selection, may have been introduced. ${ }^{16,17}$

Estonia, Norway and Sweden differ in their organization of health care and the community pharmacy sector. ${ }^{18-20}$ Detailed information concerning operation of community pharmacies and drug prescribing systems is presented in Table 1.

The objective of the study was to evaluate the feasibility of a generic instrument to document prescription problems requiring contact with prescriber before dispensing. The study was organized: (1) by countries: Estonia, Norway and Sweden; (2) by type of prescriptions: handwritten prescriptions, printouts of prescriptions in the electronic medical record and electronically transmitted prescription to pharmacies and (3) by recording method - self-completed by pharmacists or recording by independent observers.

\section{METHODS}

In Norway the protocol was self-completed by dispensing pharmacists at 9 community pharmacies located in the western and eastern regions of the country. The study was undertaken over the course of 5 weeks, 25 weekdays per pharmacy in September and October $2004 .^{21}$

In Estonia, the protocol was completed by independent observers (trained pharmacy students). Data were collected over a period of 6 weeks and 30 weekdays per pharmacy in January, July and September 2006. Four community pharmacies located near GP centres or in ambulatory clinics in 3 larger cities participated in the study. 22

In Sweden the protocol was used in a study with 7 community pharmacies in large cities in the middle and northern part of country. ${ }^{17}$ The protocol was completed by independent observers (trained pharmacy students) over the course of three consecutive weeks, 15 weekdays, per pharmacy from February 2007 to February 2008.

The protocol and form, originally developed in the USA, has been translated and adapted to the Scandinavian context by one of the authors (SH). ${ }^{21,23}$ The Estonian translation was piloted for 3 days at one community pharmacies that later 


\begin{tabular}{|c|c|c|c|}
\hline Country & Estonia & Norway & $\begin{array}{c}\text { Sweden (at the time of the } \\
\text { study) }\end{array}$ \\
\hline Population (01.01.2011) & 1340100 & 4920305 & 9428100 \\
\hline $\begin{array}{l}\text { Number of community } \\
\text { pharmacies (2011) }\end{array}$ & $\begin{array}{c}510 \\
\begin{array}{c}\text { One pharmacy per } 2627 \\
\text { inhabitants }\end{array}\end{array}$ & $\begin{array}{c}\sim 700 \\
\begin{array}{c}\text { One pharmacy per } 7000 \\
\text { inhabitants }\end{array}\end{array}$ & $\begin{array}{l}\sim 900 \\
\text { One pharmacy per } 10.500 \\
\text { inhabitants }\end{array}$ \\
\hline $\begin{array}{l}\text { Ownership of community } \\
\text { pharmacies }\end{array}$ & $\begin{array}{c}\text { Private, } \sim 85 \% \text { in } \\
\text { pharmacy chains or } \\
\text { working in cooperation } \\
\text { with chains }\end{array}$ & $\begin{array}{c}\text { Private, in pharmacy } \\
\text { chains or working in } \\
\text { cooperation with chains } \\
\text { (32 public sector hospital } \\
\text { pharmacies) }\end{array}$ & $\begin{array}{c}\text { At the time of the study all } \\
\text { pharmacies were owned } \\
\text { by the government and } \\
\text { part of the National } \\
\text { corporation of Swedish } \\
\text { Pharmacies }\end{array}$ \\
\hline $\begin{array}{l}\text { Computer software used at } \\
\text { community pharmacies }\end{array}$ & $\begin{array}{c}\text { 2-3 different types, } \\
\text { available for not only chain } \\
\text { pharmacies }\end{array}$ & $\begin{array}{l}\text { All pharmacies use } \\
\text { FarmaPro program }\end{array}$ & $\begin{array}{c}\text { At the time of the study all } \\
\text { pharmacies used the same } \\
\text { soft-ware }\end{array}$ \\
\hline E-prescription & Since 2010 & Since 2011 & $\begin{array}{c}\text { Since } 1983 ;>85 \% \text { of all } \\
\text { new prescriptions at the } \\
\text { time of the study }\end{array}$ \\
\hline Telephone and fax prescriptions & No & Yes & Yes \\
\hline Printed prescriptions & $\begin{array}{l}\text { Yes, primary and } \\
\text { secondary care }\end{array}$ & $\begin{array}{l}\text { Yes, primary and } \\
\text { secondary care }\end{array}$ & Yes \\
\hline Handwritten prescriptions & $\begin{array}{l}\text { Yes, to some extent in } \\
\text { secondary care }\end{array}$ & Yes & Yes \\
\hline Legal prescription form & Yes & Yes & Yes \\
\hline $\begin{array}{l}\text { Use of electronic medical record } \\
\text { of patient by prescriber }\end{array}$ & Yes & Yes & Yes \\
\hline $\begin{array}{l}\text { Access to electronic medical } \\
\text { record of patient at pharmacy }\end{array}$ & No & No & No \\
\hline
\end{tabular}

participated in the study. The Swedish version was piloted by independent observers in a pre-study at 4 community pharmacies for 2 weeks per pharmacy. One author in each country scrutinised the protocols. Classification problems and irregularities in classification were discussed with the observers for consensus and consistency.

Prescriptions on medications to humans with errors, ambiguities or other problems, where the pharmacist judged it necessary to contact the prescriber for clarification, correction, completion or change before dispensing were included in the study. All attempts to contact the prescribers were recorded whether or not they resulted in an actual contact.

The prescription problems were categorised as:

1. Administrative errors - technical errors concerning information about the prescriber or the patient, missing or erroneous date, reimbursement issues;

2. Problems with clinical significance inappropriate medication or indication; inappropriate strength, dose or administration form of medication; adverse drug reactions or drug-drug interactions; insufficient information concerning use of medication (instruction for use, quantity, duration of treatment);

3. Other problem - mostly those involving delivery - prescription of an unlicensed medication; unavailability of the licensed medication on the market, out of stock at the wholesaler or at the pharmacy.

Categorisation of the prescription problems was initially performed by one of the authors $(A E)$ and was reviewed and discussed with the other authors $(\mathrm{SH})$ and (DV).
The initial analysis of the data was performed in a spread sheet (Microsoft Excel@). For statistical analysis program Statistical Package for Social Sciences (SPSS, Version 11.0, Chicago, IL) was used. Two-way Anova was used to calculate the probability of incidence of different types of errors with different type of prescription and context (Estonia, Norway, Sweden). Type of prescription error was used as dependent variable, prescription type and country were used as fixed factors. Post hoc tests were used to perform detailed analysis for prescription error, country and prescription type. The statistical significance level was set to $P \leq 0.05$.

\section{RESULTS}

For $732(0.51 \%)$ of all dispensed prescriptions, 194 $(1.47 \%)$ in Estonia, $311(0.45 \%)$ in Norway and 229 $(0.38 \%)$ in Sweden, the pharmacists judged it necessary to contact the prescriber for clarification before dispensing.

About $80 \%$ of the problem prescriptions were new prescriptions. There was statistically significant difference $(p<0.001)$ in the types of prescriptions requiring contact with prescriber between Estonia, Norway and Sweden. Handwritten prescriptions constituted $73.2 \%$ in Estonia, $10.9 \%$ in Norway and $9.2 \%$ in Sweden. In Norway, the majority of the problem prescriptions were printouts of prescriptions in the electronic medical record and in Sweden more than half of the prescriptions were electronically transmitted prescriptions to pharmacies (Table 2).

There were statistically significant differences between the countries for problems with selection of medication or incorrect indication $[F(2)=7.979$; $p<0.001)$, and dosage schedule $(F(2)=5.333$; $\mathrm{p}<0.001)$. For problems with incorrect medication or 


\begin{tabular}{|l|c|c|c|}
\hline Table 2. Description of prescriptions that required contact with the prescriber before dispensing \\
\hline & $\begin{array}{c}\text { Estonia } \\
(\mathrm{n}=4)\end{array}$ & $\begin{array}{c}\text { Norway } \\
(\mathrm{n}=9)\end{array}$ & $\begin{array}{c}\text { Sweden } \\
(\mathrm{n}=7)\end{array}$ \\
\hline Dispensed prescriptions & 13,221 & 69,315 & 59,901 \\
\hline Contact with prescriber before dispensing & $\begin{array}{c}194 \\
(1.47 \%)\end{array}$ & $\begin{array}{c}311 \\
(0.45 \%)\end{array}$ & $\begin{array}{c}229 \\
(0.38 \%)\end{array}$ \\
\hline Handwritten prescriptions & $\begin{array}{c}142 \\
(73.2 \%)\end{array}$ & $\begin{array}{c}31 \\
(10.0 \%)\end{array}$ & $17(7.4 \%)$ \\
\hline $\begin{array}{l}\text { Printouts of prescriptions written in the electronic medical record- } \\
\text { printouts }\end{array}$ & $\begin{array}{c}52 \\
(26.8 \%)\end{array}$ & $\begin{array}{c}273 \\
(87.8 \%)\end{array}$ & $\begin{array}{c}77 \\
(33.6 \%)\end{array}$ \\
\hline Electronically transmitted prescription & - & - & 128 \\
& & $6(1.9 \%)$ & $7(3.1 \%)$ \\
\hline $\begin{array}{l}\text { Prescription is not classified as handwritten prescriptions, printouts } \\
\text { of prescriptions written in the electronic medical record, } \\
\text { electronically transmitted prescription }\end{array}$ & & 6 & $7.96)$ \\
\hline
\end{tabular}

indication, the post hoc analysis revealed statistically significant differences between a) Estonia and Norway, and b) Estonia and Sweden $(p<0.01)$. There were also differences for 'dosage schedule problems' between a) Estonia and Sweden, and b) Norway and Sweden. Although not statistically significant, there was a trend that clinically important errors were more common with electronically transmitted prescriptions compared with printouts of prescriptions in the electronic medical record printouts and handwritten prescriptions.

Estonia had the highest incidence of administrative errors due to the high proportion of handwritten prescriptions (Table 3). Statistically significant correlations were observed between missing information about the patient and a) prescription type $(F(2)=6.326 ; \quad p<0.01)$ and b) country $(F(2)=7.679 ; \quad p<0.01)$. Post hoc analysis demonstrated statistically significant differences for handwritten prescriptions, printouts of prescriptions in the electronic medical record and electronically transmitted prescriptions to pharmacies $(p<0.001)$, between a) Estonia and Norway $(p=0.01)$ and $b)$ Estonia and Sweden $(p<0.001)$.

Delivery problems were common in all three countries (Table 3 ).
There was statistically significant difference in successful contact of the pharmacists with prescriber in Estonia, Norway and Sweden $(p<0.05)$. The pharmacist did not succeed to reach the prescriber for $15(7.8 \%)$ of the cases in Estonia, $71(22.8 \%)$ in Norway and $63(27.5 \%)$ in Sweden. In Estonia the most common outcome was "no dispensing of the drug" (4 cases) or "dispensed as prescribed" (5 cases). In Sweden, contact with another physician, with a nurse at the ward/surgery, with a secretary or making a different intervention constituted $1 / 4^{\text {th }}$ each of these instances. In Norway, for 39 (54.9\%) cases the prescription was changed and dispensed and the prescriber was contacted afterwards.

When the pharmacists contacted the prescriber, the pharmacist's suggestions were approved by the prescriber in $68.8 \%$ of the cases in Estonia, $69.1 \%$ in Norway and $67.0 \%$ in Sweden.

\section{DISCUSSION}

Several independent studies using different protocols have documented the detection of prescription problems by community pharmacists and their interventions to solve them. ${ }^{5-9,11}$ As far as the authors of this article know this is the first international study using a generic study instrument to identify the patterns and magnitude of prescription errors in different contexts.

\begin{tabular}{|c|c|c|c|c|c|c|c|c|}
\hline & \multicolumn{2}{|c|}{ Estonia $(n=194)$} & \multicolumn{2}{|c|}{ Norway $(n=311)$} & \multicolumn{2}{|c|}{ Sweden $(n=229)$} & \multicolumn{2}{|c|}{ Two-way Anova } \\
\hline & $\mathrm{n}$ & $\%$ & $\mathrm{n}$ & $\%$ & $\mathrm{n}$ & $\%$ & $F_{(d f)}$ & $P$ \\
\hline Incorrect medication & 73 & 38.7 & 131 & 42.1 & 106 & 46.3 & & \\
\hline Incorrect medication/indication & 6 & 3.1 & 42 & 13.5 & 55 & 24.0 & $F_{(2)}=7.979$ & $p<0.001$ \\
\hline Incorrect strength of medication & 32 & 16.5 & 35 & 11.3 & 13 & 5.7 & $F_{(2)}=1.485$ & NS \\
\hline Incorrect administration form & 10 & 5.2 & 10 & 3.2 & 20 & 8.7 & $F_{(2)}=0.327$ & NS \\
\hline Treatment period/number of doses & 17 & 8.8 & 38 & 12.2 & 13 & 5.7 & $F_{(2)}=0.785$ & NS \\
\hline Contraindication & 2 & 1.0 & 2 & 0.6 & 2 & 0.9 & NA & NA \\
\hline Drug-drug interaction & 5 & 2.6 & 4 & 1.3 & 3 & 1.3 & NA & NA \\
\hline ADR/toxicity & 3 & 1.5 & - & - & - & - & NA & NA \\
\hline Delivery problems & 29 & 14.9 & 43 & 13.8 & 45 & 19.7 & NA & NS \\
\hline Schedule/instructions for use & 24 & 12.4 & 76 & 24.4 & 65 & 28.4 & & \\
\hline Schedule & 13 & 6.7 & 39 & 12.5 & 60 & 26.2 & $F_{(2)}=5.333$ & $\mathrm{p}<0.01$ \\
\hline Instructions for use & 11 & 5.7 & 37 & 11.9 & 5 & 2.2 & $F_{(2)}=2.864$ & NS \\
\hline Administrative errors & 96 & 49.5 & 121 & 38.9 & 21 & 9.2 & & \\
\hline Patient & 30 & 15.5 & 19 & 6.1 & 2 & 0.9 & $F_{(2)}=6.326$ & $\mathrm{p}<0.01$ \\
\hline Wrong patient & - & - & 3 & 1.0 & 1 & 0.4 & NA & NA \\
\hline Prescriber & 42 & 21.6 & 44 & 14.1 & 2 & 0.9 & $F_{(2)}=7.679$ & $p<0.01$ \\
\hline Reimbursement of price of medication & 24 & 12.4 & 55 & 17.7 & 16 & 7.0 & $F_{(2)}=0.375$ & NS \\
\hline Total (errors) & 222 & & 371 & & 237 & & & \\
\hline Errors per prescription & 1.1 & & 1.1 & & 1.0 & & & \\
\hline $\begin{array}{l}\text { NA - not applicable } \\
\text { NS - not significant }\end{array}$ & & & & & & & & \\
\hline
\end{tabular}


The study instrument was comprehensive with respect to recording different types of prescription errors or omissions (including adaptation to record new problems and errors associated with printouts of prescriptions written in the electronic medical record and electronically transmitted prescriptions), actions taken by the pharmacist and the outcome. The study instrument in this study could be used in everyday practice at community pharmacies for selfcompletion of recording of prescription problems or for research purposes to evaluate more complex questions.

The pattern of prescription errors with potential clinical hazards varied by country, but appeared to be similar with all types of prescriptions. However this is not confirmed by other studies. ${ }^{14,24,25}$

In the current study, only few cases of drug-drug interactions were detected, contrasting the results in studies using prescription databases. ${ }^{26,27}$ The difference may to some extent depend on that in Estonia and Sweden pharmacists at the time of the study had access to patients' pharmacy record for identification of possible interactions between the new prescription medications and those dispensed previously. In Belgium, pharmacists could access patients' records and this increased their professional independence in handling prescription errors, a result supported by the other studies. ${ }^{28}$

The incidence of administrative errors was directly associated with how the prescriptions were generated similar to the findings in other studies. $^{29,30}$ In Estonia and Norway, electronically transmitted prescription had not been introduced at the time of the study, and the number of administrative errors was higher than in Sweden, with a high proportion of electronically transmitted prescription.

The generic instrument used has not been validated against any standard as the authors did not find any standards to use. However, the classification was validated by different means in consensus discussions in all three countries.

It should be emphasized that problems in the study only represent a fraction of all prescription problems. The current selection of problem prescriptions can be explained by desire to focus on problems in the content of the prescription, rather than administrative or technical errors.

It was not possible to calculate the relative incidence of problem prescriptions for handwritten prescriptions, printouts of prescriptions written in the electronic medical record-printouts and electronically transmitted prescriptions, as dispensing data are not available for the different prescription types. However, the classification of different prescription types was undertaken only for the purposes of the current study; by the study observers in Estonia for all problem prescriptions identified during the study period and in Norway and Sweden for problem prescription requiring contact with the prescriber.
Moreover, the data collection and the protocol was used in different modes - self-completed in Norway and independent observers in Estonia and Sweden - why the results may not be totally comparable. However, the differences in the number of recorded prescription problems are associated with prescription type rather than recording method. It is also reasonable to assume that adherence to the self-reporting protocol decreases in periods of high work-load compared to studies performed by an independent observer. ${ }^{31}$ Moreover, the participating pharmacies were not randomly selected and may thus not be representative for all pharmacies within each country.

The studies in three countries were also undertaken in different years. However, it was more important to find a period in which no major reforms were taking place in the community pharmacy sector or drug prescribing system than to undertake parallel studies.

The objective was to evaluate the feasibility of using a generic instrument for documentation and classification of problem prescriptions in different contexts, not to compare the incidence of prescription errors. The presented results illustrate more the feasibility of the generic protocol to document and classify prescription problems. The presented data should not be generalized to problem incidence in the individual countries.

\section{CONCLUSIONS}

The generic protocol was shown to be appropriate and feasible to document prescription problems in different contexts involving country, prescription type, the pattern and number of prescription problems and recording methods. The study revealed differences in the pattern and number of prescription problems in Estonia, Norway and Sweden. The number of problem prescriptions was three times higher in Estonia compared with Norway and Sweden, mainly because of the high frequency of handwritten prescriptions. Electronically transmitted prescription to pharmacies may reduce the total number of prescribing errors - e.g. administrative errors as well as errors of clinical importance, but may also introduce new clinically important errors, such as selection of inappropriate medication.

Some aspects of health care system organization (type of prescription, pharmacists' access to patients' medical record) may have direct impact on the content, number and handling of prescription problems. Access to the patients' medical record could increase the detection of possible adverse drug reactions and drug-drug interactions.

\section{CONFLICT OF INTEREST}

All authors declare that they have no conflicts of interest relevant to the subject of the manuscript.

No external sources of funding were sought or obtained to conduct this study. 
1. Dean B, Barber N, Schachter M. What is a prescribing error? Qual Health Care. 2000;9(4):232-237.

2. Kuo GM, Phillips RL, Graham D, Hickner JM. Medication errors reported by US family physicians and their office staff. Qual Saf Health Care. 2008;17(4):286-290.

3. Council of Europe. Creation of a better medication safety culture in Europe: Building up safe medication practices. Expert Group on Safe Medication Practices (P-SP-PH-SAFE) (2006). Available from http://www.coe.int/t/e/social_cohesion/soc-sp/Medication\%20safety\%20culture\%20report\%20E.pdf (Accessed April 14, 2011).

4. Baciu A, Stratton K, Burke SP, eds. The Future of Drug Safety. Promoting and Protecting the Health of the Public. Washington: The National Academies Press; 2007.

5. Hawksworth GM, Corlett AJ, Wright DJ, Chrystyn H. Clinical pharmacy interventions by community pharmacists during the dispensing process. Br J Clin Pharmacol. 1999;47(6):695-700.

6. Buurma H, De Smet PA, Leufkens HG, Egberts AC. Evaluation of the clinical value of pharmacists' modifications of prescription errors. Br J Clin Pharmacol. 2004;58(5):503-511.

7. Claesson C, Burman K, Nilsson JLG, Vinge E. Prescription errors detected by Swedish pharmacists. Int J Pharm Pract. 1995;3,151-156.

8. Hulls V, Emmerton L. Prescription interventions in New Zealand community practice. J Soc Admin Pharm 1996;13:198204.

9. Rupp MT, DeYoung M, Schondelmeyer SW. Prescribing problems and pharmacist interventions in community practice. Med Care. 1992;30(10):926-940.

10. Benrimoj SI, Langford JH, Berry G, Collins D, Lauchlan R, Stewart K, Aristides M, Dobson M. Economic impact of increased clinical intervention rates in community pharmacy. A randomised trial of the effect of education and a professional allowance. Pharmacoeconomics. 2000;18(5):459-468.

11. Buurma $\mathrm{H}$, de Smet PA, van den Hoff OP, Egberts AC. Nature, frequency and determinants of prescription modifications in Dutch community pharmacies. Br J Clin Pharmacol. 2001;52(1):85-91.

12. Shah NH, Aslam M, Avery AJ. A survey of prescription errors in general practice. Pharm J 2001;(267):860-862.

13. Westein MP, Herings RM, Leufkens HG. Determinants of pharmacists' interventions linked to prescription processing. Pharm World Sci. 2001;23(3):98-101.

14. Varkey P, Aponte P, Swanton C, Fischer D, Johnson SF, Brennan MD. The effect of computerized physician-order entry on outpatient prescription errors. Manag Care Interface. 2007;20(3):53-57.

15. Gil de San Vicente O, Erauncetamurgil O, de Escalza P, Odriozola I, Gastelurrutia MA. Assessment of poorly written prescriptions that reach a community pharmacy. Seguimiento Farmacoterapeutico 2005;3(3);125-129.

16. Astrand B, Montelius E, Petersson G, Ekedahl A. Assessment of ePrescription quality: an observational study at three mail-order pharmacies. BMC Med Inform Decis Mak. 2009;9:8.

17. Ekedahl A. Problem prescriptions in Sweden necessitating contact with the prescriber before dispensing. Res Social Adm Pharm. 2010;6(3):174-184.

18. Westerlund LT, Björk HT. Pharmaceutical Care in Community Pharmacies: Practice and Research in Sweden. Ann Pharmacother. 2006;40(6):1162-1169.

19. Almarsdottir AB, Traulsen JM. Multimethod research into policy change in the pharmacy sector - The Nordic case. Res Social Adm Pharm. 2009;5(1):82-90.

20. Volmer D, Vendla K, Vetka A, Bell JS, Hamilton D. Pharmaceutical care in community pharmacies: practice and research in Estonia. Ann Pharmacother. 2008;42(7):1104-1111.

21. Haavik S, Horn AM, Mellbye KS, Kjønniksen I, Granås AG. Forskrivningsfeil - omfang og oppklaring. Tidsskr Nor Laegeforen. 2006 26;126(3):296-298.

22. Volmer D, Haavik S, Ekedahl A, Veski P. Probleemsed retseptid, mille alusel ravimi väljastamine apteegist nõuab konsultatsiooni ravimi ordineerijaga Eesti, Norra ja Rootsi võrdlusuuringu põhjal. Eesti Arst. 2010;89,5-12.

23. Kennedy AG, Littenberg B. A modified outpatient prescription form to reduce prescription errors. Jt Comm J Qual Saf. 2004;30(9):480-487.

24. Oliven A, Michalake I, Zalman D, Dorman E, Yeshurun D, Odeh M. Prevention of prescription errors by computerized, on-line surveillance of drug order entry. Int J Med Inform. 2005;74(5):377-386.

25. Koppel R, Metlay JP, Cohen A, Abaluck B, Localio AR, Kimmel SE, Strom BL. Role of computerized physician order entry systems in facilitating medication errors. JAMA. 2005;293(10):1197-1203.

26. Astrand B, Astrand E, Antonov K, Petersson G. Detection of potential drug interactions - a model for a national pharmacy register. Eur J Clin Pharmacol. 2006;62(9):749-756.

27. Johnell K, Klarin I. The relationship between number of drugs and potential drug-drug interactions in the elderly: a study of over 600,000 elderly patients from the Swedish Prescribed Drug Register. Drug Saf. 2007;30(10):911-918.

28. Leemans L, Veroeveren L, Bulens J, Hendrickx C, Keyenberg W, Niesten F, Vandeberg J, Van Hoof J, Laekeman G. Frequency and trends of interventions of prescriptions in Flemish community pharmacies. Pharm World Sci. 2003;25(2):65-69.

29. Lynskey D, Haigh SJ, Patel N, Macadam AB. Medication errors in community pharmacy: an investigation into the types and potential causes. Int J Pharm Pract 2007;15(2):105-112.

30. Bizovi KE, Beckley BE, McDade MC, Adams AL, Lowe RA, Zechnich AD, Hedges JR. The effect of computer-assisted prescription writing on emergency department prescription errors. Acad Emerg Med. 2002;9(11):1168-1175.

31. Mandt I, Horn AM, Ekedahl A, Granas AG. Community pharmacists' prescription intervention practices-Exploring variations in practice in Norwegian pharmacies. Res Social Adm Pharm. 2010;6(1):6-17. 